\title{
GMR
}

\section{Effect of photoperiod on serum hormone concentrations during the annual reproductive cycle in geese}

X.Z. Zhao ${ }^{1,2 *}$, G.L. Gao ${ }^{1,2 *}$, H.W. Wang ${ }^{1,2}$, Q. Li ${ }^{1,2}$, K.S. Zhang ${ }^{1,2}$, H. Zhong ${ }^{1,2}$ and Q.G. Wang ${ }^{1,2}$

${ }^{1}$ Chongqing Academy of Animal Science, Chongqing, China

${ }^{2}$ Chongqing Engineering Research Center of Goose Genetic Improvement,

Chongqing, China

*These authors contributed equally to this study.

Corresponding author: Q.G. Wang

E-mail: wangqigui@hotmail.com

Genet. Mol. Res. 16 (1): gmr16019266

Received September 13, 2016

Accepted December 7, 2016

Published March 22, 2017

DOI http://dx.doi.org/10.4238/gmr16019266

Copyright $(2017$ The Authors. This is an open-access article distributed under the terms of the Creative Commons Attribution ShareAlike (CC BY-SA) 4.0 License.

\begin{abstract}
The poor egg-laying rate of geese hinders the development of the goose industry; therefore, the reproductive performance of geese is an important area of investigation. To evaluate the relationship between photoperiod, reproductive hormones, and reproductive activity during the egg-laying cycle in geese under natural conditions, we collected blood samples from Sichuan white geese and Xupu geese to quantify changes in prolactin (PRL), estradiol (E2), vasoactive intestinal polypeptide (VIP), follicle stimulating hormone (FSH), gonadotropin-inhibitory hormone $(\mathrm{GnIH})$, and luteinizing hormone (LH). We also calculated the rate of egg laying for the two populations during the egg-laying cycle. We show that the egg-laying rate and the serum concentration of some hormones (PRL, E2, VIP, FSH, GnIH, and LH) differed significantly between the two populations during the pre-laying, laying, and ceased-laying periods. Serum LH concentrations may be associated with maturation of the
\end{abstract}

Genetics and Molecular Research 16 (1): gmr16019266 
ovary and oviducts, whereas FSH, PRL, and GnIH play important roles in egg laying. These results provide a useful resource for future studies examining the laying rate in geese.

Key words: Goose; Reproductive hormone; Egg laying; Plasma prolactin; Estradiol; Vasoactive intestinal polypeptide

\section{INTRODUCTION}

As an economically important waterfowl, geese are reared throughout central Europe and Asia, including China (Chen et al., 2004; Pilling and Rischkowsky, 2007) to supply meat, eggs, fat, and feathers for human consumption. However, production capacity is limited by the seasonality of breeding and their relatively low reproductive performance (Shi et al., 2007). Thus, there is a need to improve the reproductive performance of geese to meet market needs.

Photoperiod is the predominant factor controlling the seasonality of reproductive activity in poultry (Sharp, 1993; Slater et al., 1997; Shi et al., 2007). Photoperiod affects the secretion of gonadotropins and prolactin from the pituitary, which, in turn, influence gonadal activity to coordinate the breeding season and determine its timing and duration (Dittami et al., 1985; Péczely et al., 1985; Shi et al., 2008). A long photoperiod decreases laying rate, whereas short photoperiods increase the laying rate in short-day breeding geese (Shi et al., 2005, 2007; Huang et al., 2008). Photoperiod and season regulate the gene expression and secretion of reproductive hormones in geese. For example, many goose genes are significantly up-regulated in the pituitary, ovaries, and hypothalamus between the pre-laying and laying periods $(\mathrm{Xu}$ et al., 2013; Luan et al., 2014; Ding et al., 2014; Gao et al., 2014, 2015). Furthermore, the concentrations of plasma prolactin (PRL), luteinizing hormone (LH), progesterone (P4), and estradiol (E2) differ significantly in geese between the pre-laying, laying, and ceased-laying periods (Shi et al., 2004, 2007; Fang et al., 2009; Gumułka and Rozenboim, 2015b). Gonadal steroid hormones are closely related to egg laying in geese under natural photoperiods (Shi et al., 2008); however, the relationships between photoperiod, reproductive hormones, and reproductive activity in geese remain poorly understood.

To investigate broodiness characteristics, we evaluated the relationship between hormones, egg laying, and photoperiod in Sichuan white geese, which have a high egg-laying rate, and Xupu geese, which have a low-laying rate. We measured egg laying and PRL, E2, vasoactive intestinal polypeptide (VIP), follicle stimulating hormone (FSH), gonadotropininhibitory hormone $(\mathrm{GnIH})$, and LH between the ages of 10 and 64 weeks. Our results provide insights into the effect of photoperiod on serum hormone concentrations and laying rate during the annual reproductive cycle in Sichuan white geese and Xupu geese.

\section{MATERIAL AND METHODS}

\section{Statement of ethics}

The study protocol was reviewed and approved by the Research Ethics Committee and the Animal Ethical Committee of Chongqing Academy of Animal Sciences, and was performed according to guidelines of the Laboratory Animal Management Committee of Chongqing Academy of Animal Sciences.

Genetics and Molecular Research 16 (1): gmr16019266 


\section{Animals}

We used female Sichuan white geese $(\mathrm{N}=301)$ and female Xupu geese $(\mathrm{N}$ = 297) hatched on March 8, 2014. These geese were raised at the waterfowl-breeding base in Rongchang County, Chongqing City, China $\left(105.6^{\circ} \mathrm{N}, 29.4^{\circ} \mathrm{E}\right)$ and were reared under the same environmental conditions with free access to water and $200 \mathrm{~g}$ commercial corn- and soybean-based diets each day. The number of eggs laid by the two populations was calculated at the same time every day. Photoperiod was calculated using data from Chongqing Meteorological Bureau, Chongqing City, China.

\section{Blood samples}

We collected blood samples from Sichuan white geese and Xupu geese using 5-mL vacuum tubes containing heparin $(100 \mathrm{mg} / \mathrm{L}$ ) during the pre-laying (weeks 10, 14, 18, 22, $24,26,28$, and 30) laying (weeks 32, 45, and 58), and ceased-laying periods (week 64) (N $=20$ randomly selected individuals per time period for each breed). The tubes were kept chilled but were not frozen until they were centrifuged at $3500 \mathrm{~g}$ for $15 \mathrm{~min}$. The serum (1 $\mathrm{mL}$ ) was removed and stored at $-20^{\circ} \mathrm{C}$ until analysis.

\section{Hormone assays}

Serum PRL, E2, VIP, FSH, GnIH, and LH concentrations were determined by radio-immunoassay by Beijing Lembo Terry Technology Development Co. (Beijing, China) using a PRL Radioimmunoassay Kit (LBTR-10025) (Lembo), an E2 Radioimmunoassay Kit (LBTR-10028) (Lembo), a VIP Radioimmunoassay Kit (LBTR-10162) (Lembo), an FSH Radioimmunoassay Kit (LBTR-10023) (Lembo), and an LH Radioimmunoassay Kit (LBTR-10024) (Lembo). The assay standard ranges were 125-2000 mIU/ $\mathrm{mL}$ for PRL, $10-2000 \mathrm{pg} / \mathrm{mL}$ for E2, $40-5120 \mathrm{pg} / \mathrm{mL}$ for VIP, $2.5-100 \mathrm{mIU} / \mathrm{mL}$ for FSH, and $2.5-100 \mathrm{mIU} / \mathrm{mL}$ for $\mathrm{LH}$. The assay sensitivities were $40 \mu \mathrm{IU} / \mathrm{mL}$ for PRL, $5 \mathrm{pg} /$ $\mathrm{mL}$ for E2, $0.4 \mathrm{pg} / \mathrm{mL}$ for VIP, $1.0 \mathrm{mIU} / \mathrm{mL}$ for FSH, and $1.0 \mathrm{mIU} / \mathrm{mL}$ for $\mathrm{LH}$. Both the intra- and inter-assay coefficients of variation for PRL, VIP, FSH, GnIH and LH were less than $10 \%$, and the intra- and inter-assay coefficients of variation for E2 were 10 and $15.2 \%$, respectively.

Serum concentrations of GnIH were measured by Beijing Lembo Terry Technology Development Co. (Beijing, China) using a GnIH Elisa Kit (LBTR-10023) according to the manufacturer instructions.

\section{Data analysis}

The egg-laying rate was calculated as the average number of eggs laid per day over a week. Data are expressed as the means \pm SD. Differences in laying rate and levels of reproductive hormones at each laying time between the two goose populations were analyzed using the Student $t$-test. Differences were considered highly significant or significant at $\mathrm{P} \leq 0.01$ or $\mathrm{P} \leq 0.05$, respectively. The relationships between photoperiod, laying rate, and reproductive hormones were evaluated using Pearson correlation coefficients. 


\section{RESULTS}

\section{Serum PRL, E2, VIP, FSH, GnIH, and LH concentrations}

The serum concentrations of PRL, E2, VIP, FSH, GnIH, and LH in the two populations are given in Figure 1. PRL concentrations increased steadily between the pre-laying and ceased-laying periods (Figure 1A). Serum PRL levels were significantly lower in Sichuan white geese at 45, 58, and 64 weeks compared with Xupu geese $(\mathrm{P}<0.01)$ (Figure 1A).

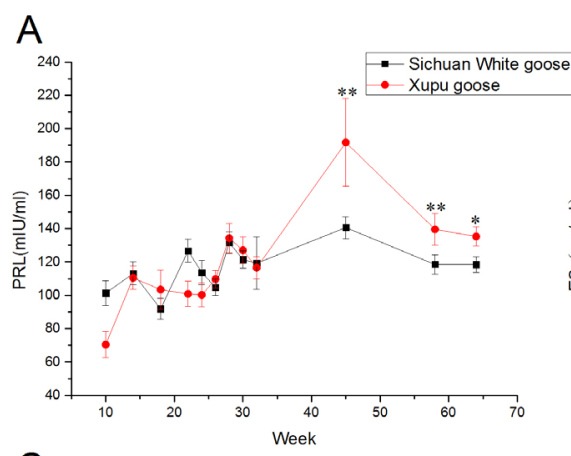

C
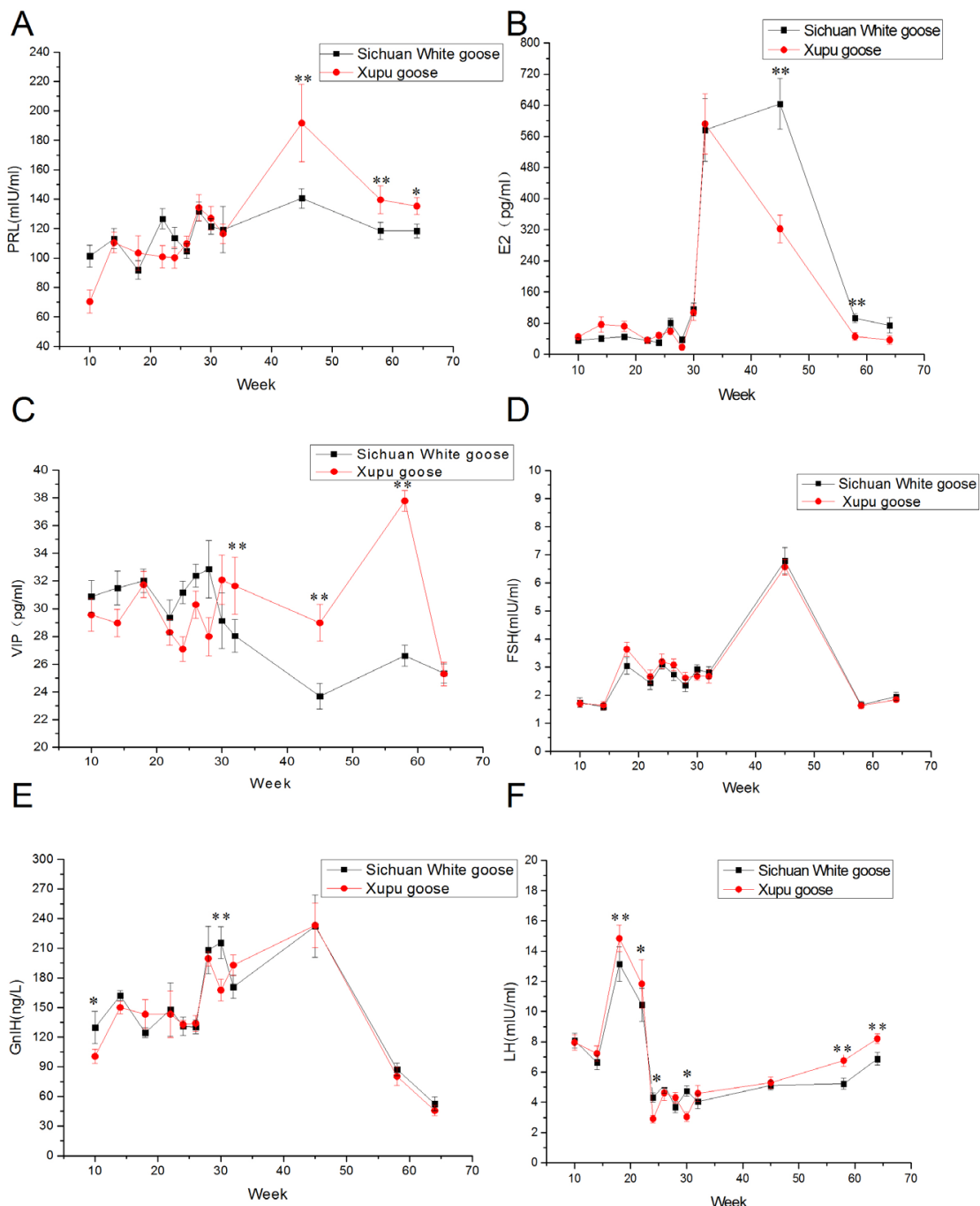

Figure 1. Changes in blood serum concentrations of PRL (A), E2 (B), VIP (C), FSH (D), GnIH (E), and LH (F) in Sichuan white geese and Xupu geese from week 10 to 64 . **Highly significant difference at $\mathrm{P} \leq 0.01$; *significantly different at $\mathrm{P} \leq 0.05 . \mathrm{PRL}=$ prolactin; $\mathrm{E} 2=$ estradiol; $\mathrm{VIP}=$ vasoactive intestinal polypeptide; $\mathrm{FSH}=$ follicle stimulating hormone; $\mathrm{GnIH}=$ gonadotropininhibitory hormone; $\mathrm{LH}=$ luteinizing hormone.

Genetics and Molecular Research 16 (1): gmr16019266 
Serum E2 concentrations increased steadily in the pre-laying period, increased rapidly in the laying period, then decreased rapidly in the ceased-laying period (Figure 1B). Serum E2 concentrations were significantly higher in Sichuan white geese at weeks 45 and 58 compared with Xupu geese $(\mathrm{P}<0.01$ or $\mathrm{P}<0.05)$ (Figure 1B).

Serum VIP concentrations remained steady in the pre-laying and laying periods, before peaking in the late-laying period and decreasing to minimal levels in the ceased-laying period in Sichuan white geese. Conversely, the minimum serum VIP level observed in Xupu geese occurred during the laying period (Figure 1C). Serum VIP concentrations were significantly lower in Sichuan white geese at 32, 45, and 58 weeks than in Xupu geese $(\mathrm{P}<0.01)$ (Figure 1C).

Serum FSH concentrations increased steadily in the pre-laying period, increased rapidly in the laying period, then decreased rapidly in the ceased-laying period (Figure 1D). Serum FSH concentrations were similar between the two populations at all time points (Figure 1D).

Serum GnIH concentrations increased steadily during the pre-laying and peak-laying periods (week 45), but decreased to minimal levels during the ceased-laying period (Figure 1E). GnIH concentrations were significantly higher in Sichuan white geese at weeks 10 and 30 than in Xupu geese $(\mathrm{P}<0.01)$ (Figure 1E).

Serum LH concentration increased rapidly from week 10 to week 18 (peak), then began to fall sharply during the pre-laying period, before increasing slightly during the laying and ceased-laying periods. The serum LH concentration was significantly higher in Sichuan white geese at weeks 24 and 30 compared with those in Xupu geese $(\mathrm{P}<0.01)$, but significantly lower at weeks 18, 22, 58, and $64(\mathrm{P}<0.01)$ (Figure 1F).

\section{Laying rate and natural photoperiod}

The laying rate of the two populations was significantly different at all time points (Figure 1). The daylight length peaked at $14 \mathrm{~h} 2 \mathrm{~min}$ at 16 weeks, decreased to $10 \mathrm{~h} 16 \mathrm{~min}$ at 43 weeks, then increased up to 70 weeks (Figure 1). Egg laying in Sichuan white geese and Xupu geese first occurred at weeks 30 and 31, respectively. The laying rate of the two populations was significantly different $(\mathrm{P}<0.01)$ from 36 to 64 weeks, and was nearly twice as high in Sichuan white geese as in Xupu geese (Figure 2). As day length decreased, the laying rate of Sichuan white geese increased from week 30 to 43. The Pearson correlation coefficient for daylight length and laying rate was less than -0.9 for Sichuan white geese between weeks 32 and 43, and for Xupu geese between weeks 33 and 37 (Table 1). This suggests that the natural photoperiod negatively affects laying rate during sensitive periods.

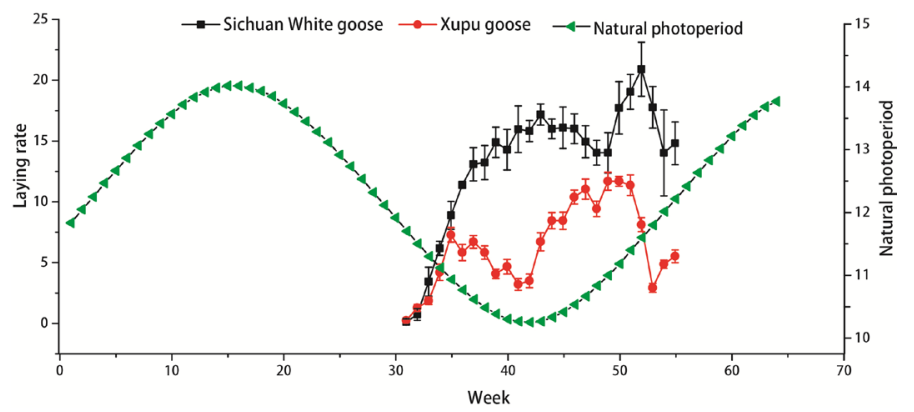

Figure 2. Changes in the natural photoperiod in Rongchang County and the laying rate of Sichuan white geese and Xupu geese. ${ }^{*}$ Highly significant difference at $\mathrm{P} \leq 0.01$.

Genetics and Molecular Research 16 (1): gmr16019266 
Table 1. Pearson correlation coefficients between photoperiod and laying rate.

\begin{tabular}{l|c|c|c}
\hline Week & Day photoperiod $(\mathrm{h})$ & Sichuan white goose & Xupu goose \\
\hline 33 & 11.30 & -0.94 & -0.99 \\
\hline 34 & 11.12 & -0.97 & -0.94 \\
\hline 35 & 10.93 & -0.98 & -0.96 \\
\hline 36 & 10.77 & -0.99 & -0.90 \\
\hline 37 & 10.62 & -0.99 & -0.90 \\
\hline 38 & 10.48 & -0.99 & -0.84 \\
\hline 39 & 10.38 & -0.99 & -0.67 \\
\hline 40 & 10.30 & -0.98 & -0.60 \\
\hline 41 & 10.27 & -0.99 & -0.45 \\
\hline 42 & 10.25 & -0.99 & -0.35 \\
\hline 43 & 10.27 & -0.99 & -0.43 \\
\hline 45 & 10.33 & -0.99 & -0.46 \\
\hline 46 & 10.42 & -0.99 & -0.48 \\
\hline 47 & 10.53 & -0.98 & -0.44 \\
\hline 48 & 10.67 & -0.97 & -0.37 \\
\hline 49 & 10.83 & -0.95 & -0.32 \\
\hline
\end{tabular}

\section{DISCUSSION}

Sichuan white geese and Xupu geese are closely related breeds, belonging to the genus Anser; however, the laying rates of the two breeds were found to be significantly different at each time point. Sichuan white geese were found to have a higher laying rate (60-70 eggs/ year) than Xupu geese ( $\sim 30$ eggs/year) (Chen et al., 2004), making the two breeds suitable models for the study of reproductive efficiency. Both populations are characterized as shortday breeding geese (Shi et al., 2008), such that increasing the length of the photoperiod inhibits reproductive activities, whereas shortening the photoperiod stimulates reproductive activities (Shi et al., 2007; Huang et al., 2008).

Egg-laying rate was used as an index of reproductive activity in the present study. Previous studies have shown that photoperiod affects the egg laying rate and levels of reproductive hormones in the plasma and serum of goose (Huang et al., 2007; Chen et al., 2012; Gumułka and Rozenboim, 2015a). We found a negative correlation between photoperiod and egg-laying rate in the first laying and peak laying periods, and decreased egg laying rates during the ceased-laying period for both species. In a previous study, we found that there was a significant difference in the egg-laying rate in Sichuan White geese between short (8-h light: 16-h dark) and natural photoperiods, or long photoperiods (16-h light: 8-h dark) (data not shown). Moreover, we found both negative and positive correlations between photoperiod and serum FSH, E2, PRL, GnIH, and LH concentrations in the two populations, suggesting that photoperiod alters hormone concentrations in order to stimulate or inhibit the egg-laying rate.

Compared with Sichuan white geese, Xupu geese exhibit strong broodiness and a lower laying rate (Chen et al., 2004). PRL plays an important role in the maintenance of broodiness in geese (Usman et al., 2014). Moreover, VIP is secreted by the hypothalamus and stimulates PRL expression and release in vivo and in vitro (Kuenzel, 2003; Al Kahtane et al., 2005). Our results indicate that serum VIP concentrations were significantly lower in Sichuan white geese during the laying period at 32, 45, and 58 weeks compared with Xupu geese ( $\mathrm{P}$ $<0.01$ ) (Figure $2 \mathrm{G}$ ). During the laying period, serum PRL concentrations were significantly lower in Sichuan white geese than in Xupu geese at weeks 45 and 58, which may explain why Xupu geese exhibit strong broodiness.

Genetics and Molecular Research 16 (1): gmr16019266 
The ovary and oviducts mature rapidly in geese prior to egg laying (Liu et al., 1995). In our study, serum LH concentrations peaked at 18 weeks and began to fall rapidly during the pre-laying period, suggesting that the changes in serum LH concentration may be associated with the maturation of the ovary and oviducts. In production, the 45 -week laying rate is typically thought to represent the peak laying rate. We found that serum FSH, PRL, and GnIH concentrations fluctuated significantly at 45 -weeks. These three hormones are involved in reproductive performance, and our data suggest that they influence the laying rate of the two breeds. Serum GnRH, and E2 concentrations were significantly higher in Sichuan white geese than in Xupu geese at 45 weeks $(P<0.01)$, and serum PRL and VIP concentrations were significantly lower in Sichuan white geese than in Xupu geese, suggesting that the difference in serum GnRH, E2, VIP, and GnIH concentrations may explain, in part, the difference in laying rate. In conclusion, photoperiod affects egg laying and serum hormone concentrations during the annual reproductive cycle of geese.

In our previous studies, we found that gene expression in the pituitary, ovaries, and hypothalamus of Sichuan White geese was significantly different between the pre-laying and laying periods. This included important reproduction genes, such as GnIH, GnRH, and VIP(Ding et al., 2014; Gao et al., 2014, 2015). We also found that artificial photoperiods affect the laying rate and the concentrations of some serum hormones (data not shown); photoperiod affected egg laying and serum hormone concentrations during the annual reproductive cycle of geese in this study. These previous studies described the phenomenon, or important reproduction-related genes in goose, however, the goose mechanism of reproduction were unclear to date. More indepth research on reproduction mechanisms in goose will be performed in the future.

In conclusion, the egg-laying rate of Sichuan white geese was found to be significantly higher than that of Xupu geese. In addition, serum LH, T, GnRH, E2, PRL, VIP, and GnIH concentrations were significantly different between the two populations during the prelaying, laying, or ceased-laying periods. Moreover, there was a negative correlation between photoperiod and egg-laying rate during the first laying and peak laying periods in the two populations. There were negative and positive correlations between photoperiod and serum FSH, E2, PRL, GnIH, and LH concentrations in the two populations.

\section{Conflict of interest}

The authors declare no conflict of interest.

\section{ACKNOWLEDGMENTS}

Research supported by the National Natural Science Fund of China (Grant \#31572386), the Chongqing foundation and advanced research project (Grant \#cstc2014jcyjA80021), the Chongqing Fundamental Research Funds Projects (Grant \#14454), and the Earmarked Fund for China Agriculture Research System (Grant \#CARS-43-43).

\section{REFERENCES}

Al Kahtane A, Kannan M, Kang SW and El Halawani ME (2005). Regulation of prolactin gene expression by vasoactive intestinal peptide and dopamine in the turkey: role of Ca signalling. J. Neuroendocrinol. 17: 649-655. http://dx.doi. org/10.1111/j.1365-2826.2005.01352.x

Genetics and Molecular Research 16 (1): gmr16019266 
Chen GH, Wang KH, Wang JY, Ding C, et al. (2004). Poultry genetic resources in China. Shanghai Scientific and Technological Press, Shanghai, China.

Chen Y, Cai F, Yang H, Wang Z, et al. (2012). Variation of serum biochemical parameters and reproductive hormone levels of breeding goose in natural photoperiod. China Poultry 34: 34-37.

Ding N, Han Q, Li Q, Zhao X, et al. (2014). Comprehensive analysis of Sichuan white geese (Anser cygnoides) transcriptome. Anim. Sci. J. 85: 650-659. http://dx.doi.org/10.1111/asj.12197

Dittami JP, Goldsmith AR and Follett BK (1985). Seasonal changes in follicle-stimulating hormone in a breeding population of barheaded geese, Anser indicus. Gen. Comp. Endocrinol. 57: 195-197. http://dx.doi.org/10.1016/00166480(85)90263-1

Fang DA, Geng ZY, Luo ZH, Wang AP, et al. (2009). Research on change pattern of PRL, E2, P4 and LH in Wan-xi white goose reproduction cycle. J. Shangrao Normal Univ. 3: 020.

Gao G, Li Q, Zhao X, Ding N, et al. (2015). Transcriptome profiling of the hypothalamus during prelaying and laying periods in Sichuan white geese (Anser cygnoides). Anim. Sci. J. 86: 800-805. http://dx.doi.org/10.1111/asj.12356

Gao GL, Zhao XZ, Li Q, Su J, et al. (2014). Gene expression profiles in the pituitary glands of Sichuan White geese during prelaying and laying periods. Genet. Mol. Res. 14: 12636-12645. http://dx.doi.org/10.4238/2015.October.19.7

Gumułka M and Rozenboim I (2015a). Effect of breeding stage and photoperiod on gonadal and serotonergic axes in domestic ganders. Theriogenology 84: 1332-1341. http://dx.doi.org/10.1016/j.theriogenology.2015.07.012

Gumułka M and Rozenboim I (2015b). Breeding period-associated changes in semen quality, concentrations of LH, PRL, gonadal steroid and thyroid hormones in domestic goose ganders (Anser anser f. domesticus). Anim. Reprod. Sci. 154: 166-175. http://dx.doi.org/10.1016/j.anireprosci.2014.11.021

Huang YM, Shi ZD, Li XW, Liu Z, et al. (2007). Effect of photoperiod on the seasonal changes of laying, plasma PRL and LH in Magang geese. J. South China Agric. Univ. 3: 022.

Huang YM, Shi ZD, Liu Z, Liu Y, et al. (2008). Endocrine regulations of reproductive seasonality, follicular development and incubation in Magang geese. Anim. Reprod. Sci. 104: 344-358. http://dx.doi.org/10.1016/j.anireprosci.2007.02.005

Kuenzel WJ (2003). Neurobiology of molt in avian species. Poult. Sci. 82: 981-991. http://dx.doi.org/10.1093/ps/82.6.981

Liu Z, Liu J, Kang S, Zou F, et al. (1995). Morphological observation of the ovary and oviduct development of Xupu geese before and after laying. J. Hunan Agric. Univ 22: 381-385.

Luan X, Liu D, Cao Z, Luo L, et al. (2014). Transcriptome profiling identifies differentially expressed genes in Huoyan goose ovaries between the laying period and ceased period. PLoS One 9: e113211. http://dx.doi.org/10.1371/journal. pone. 0113211

Péczely P, Czifra G, Seprödi A and Teplán I (1985). Effect of low light intensity on testicular function in photorefractory domestic ganders. Gen. Comp. Endocrinol. 57: 293-300. http://dx.doi.org/10.1016/0016-6480(85)90274-6

Pilling D and Rischkowsky B (2007). The state of the world's animal genetic resources for food and agriculture. Food \& Agriculture Org.

Sharp PJ (1993). Photoperiodic control of reproduction in the domestic hen. Poult. Sci. 72: 897-905. http://dx.doi. org/10.3382/ps.0720897

Shi Z, Tian Y, Wu W and Wang Z (2008). Controlling reproductive seasonality in the geese: a review. Worlds Poult. Sci. J. 64: 343-355. http://dx.doi.org/10.1017/S0043933908000081

Shi ZD, Sun AD, Huang YM and Liang SD (2004). Using artificial photoperiod to control reproductive seasonality in geese: data from production trials. In: Proceedings of XXII World Poultry Congress (Vol. 952).

Shi ZD, Sun A, Huang Y and Liang S (2005). Study on photoperiodic regulation of reproductive seasonality of Guangdong greylag geese. Guangdong Agricultural Science, 3.

Shi ZD, Huang YM, Liu Z, Liu Y, et al. (2007). Seasonal and photoperiodic regulation of secretion of hormones associated with reproduction in Magang goose ganders. Domest. Anim. Endocrinol. 32: 190-200. http://dx.doi.org/10.1016/j. domaniend.2006.03.002

Slater PJ, Snowdon CT, Rosenblatt JS and Milinski M (1997). Advances in the study of behavior. Academic Press.

Usman M, Basheer A, Akram M, Babar ME, et al. (2014). Prolactin: candidate gene for egg production or broodiness traits in chicken. Sci. Int. 26.

Xu Q, Zhao W, Chen Y, Tong Y, et al. (2013). Transcriptome profiling of the goose (Anser cygnoides) ovaries identify laying and broodiness phenotypes. PLoS One 8: e55496. http://dx.doi.org/10.1371/journal.pone.0055496

Genetics and Molecular Research 16 (1): gmr16019266 